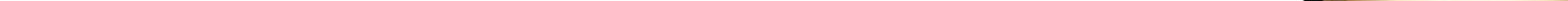




\section{Beyond the screen: Emerging cinema and engaging audiences Stephanie Janes}

Beyond the Screen returns to Andre Bazin's question 'What is Cinema?' and in answer presents a compelling overview of new cinematic forms which Atkinson terms 'emerging cinema'. This is a timely intervention and call for the reconsideration and evaluation for several concepts and terms that are becoming intertwined as cinema continues to evolve in an era of digitally networked communications and an increasingly digitally literate audience.

Beyond the Screen asks us to reconsider several overlapping relationships between the cinematic, the televisual, the theatrical, the promotional, the fictional, the 'real', the audience, the actor and the author, creator or producer. Using textual analysis, audience research and interviews with industry professionals, Beyond the Screen interrogates new permutations of the cinematic in both commercial and independent sectors, ranging from extended cinema, to mobile cinema and socially layered cinema. The complexities and potential difficulties of the approach are acknowledged, particularly regarding the highly ephemeral and experiential nature of the medium and often its audiences.

Atkinson sets up a context in which the promotional has become integral to the cinematic experience. In Chapter 2 this is traced back as far as 1920s 'Ballyhoo' promotional stunts, or 1960s novelty film marketing, highlighting that this is not something borne purely from the digital communications networks that enable many of the texts which the book focuses on. These include complex promotion ARGs and website which function to "extend and enhance" the world, textures, themes and mythology of the films they are promoting (p.26).

As these techniques have developed, so the audience has evolved to appreciate and expect a more complex, textually and temporally layered viewing experience. Atkinson even goes so far as to say that these initiatives "highlight an emerging industry imperative in which the ancillary 
material becomes a central facet of the fictional experience on a similar scale in term of audiences' expectation and anticipation as the feature film itself' (p. 27). This might initially seem an extravagant claim, but the breadth and depth of case studies presented makes Atkinson's argument compelling. Promotional campaigns for Requiem for a Dream (2000), Cloverfield (2008) and District 9 (2009), are expertly marshalled, along with independent productions such as Lance Weiler's Pandemic 1.0 (2011), Strain (2012), On_Line (2002).

Additionally, this chapter emphasises the need to acknowledge the variance in levels and kinds of engagement that are possible within emerging cinema. All too often (particularly in relation to ARGs), studies emphasise the kind of intense engagement exemplified by the '1\%' of the audience. This is the most obvious but not necessarily the most important kind of engagement that these experiences engender, and Atkinson takes care to note this.

It also highlights to extent to which cinematic "spaces... bleed into everyday life" (p. 18), a theme which recurs in the chapters on mobile and socially layered cinema. Atkinson argues that mobile cinema is not only a legitimate cultural form but is on the increase. What still remains to be seen, however, is whether it can be effectively mainstreamed and monetised. The RIDES platform in particular has seen only limited success in the three years since Beyond the Screen was initially published, and effective monetisation of these formats remains somewhat elusive, though not for want of creative ideas in a growing industry.

Socially layered cinema specifically utilises everyday modes of digital social engagement (primarily via established or constructed social media platforms) to the extent that it "becomes a centripetal and intrinsic facet of the audience experience" (p. 101), often driving and sometimes shaping the narrative. Atkinson argues that advertising modalities and televisual viewing behaviours "impact, extend and enhance immersive online cinematic experience" (p.102). This 
chapter uses The Inside Experience (2011) and Cloud Chamber (2013) as key case studies, reflecting how this occurs across both commercial and avant-garde spheres.

Both chapters highlight the recurring instances of content reflecting form, as extended cinema is made, distributed and consumed via the very technology it takes to task in its themes and concerns. This includes anxieties around digital surveillance and privacy, the impact of the personalised viewing experience, the digital self, mediated 'haunting', cyberbullying and particularly insecurities about the authenticity and veracity of a media experience which penetrates so deeply into our everyday lives.

These concerns lead neatly into the next three chapters which draw together topics which span all three categories of emerging cinema previously outlined. A medium which works explicitly to blur the boundaries between reality and fiction immediately sparks issues of ethicality, which Chapter 5 addresses. Atkinson is careful to note that this is not at attempt to draw a singular ethical framework, but rightly identifies issues around hoaxing and deception of the audience (deliberate or perceived) and difficulties around the notion of an 'unaware' audience. Again this is well grounded historically, from War of the Worlds broadcast (1938), to Forgotten Silver in 1995 and The Truth About Marika (2007).

In another configuration of the fiction/reality relationship, emerging cinema can also attempt to bring 'true realities to the audience as fictional constructs'. Beyond the Screen repeatedly highlights the emotive and active audience responses that are elicited by these new modes of cinema. This can arguably be channelled into real world problem solving, which Atkinson terms purposeful storytelling. Projects range from fossil fuel shortages and climate change (World Without Oil (2007), Future Coast (2014)) to human rights (America 2049 (2011)) and the emotional impact of growing up in the foster care system (My Sky is Falling (2012)). 
Whilst the author sees the positive effects of all these films on audiences, including their ability to inform and influence policy, she also acknowledges the relationship between 'purposeful storytelling', perceived slacktivism and reductive representations of extreme poverty in some modes of emerging cinema which may have negative effects on the communities they are intended to assist. As such, she rightly argues that both audiences and producers have increasing responsibility for the impact of their co-creations.

As boundaries blur between fiction and reality, so too are the lines between funding, distribution and consumption models, disturbing traditional models and arguably shifting established discourses of power. Atkinson also highlights the commonly made argument that such models of co-creation, involving crowdfunding or crowdsourcing of content or distribution methods can be considered exploitation of free labour. Although this is often deemed to be located primarily the commercial sphere, Atkinson argues that co-creation and co-option occur across both commercial and independent projects, and crucially that they are "not conceived as hermetic distinctions, rather bidirectional dynamic interrelationships exist between the two" (p. 174). This conception is a far more fitting of the complex reality of the industry and the examples support a much broader application of the arguments presented. This also takes an important step away from binaries which still tend to pervade in discourse surrounding audience and particularly fan labour.

The final chapter represents perhaps the strongest and most theoretical section of the book. The Grammar of Emerging Cinema starts to construct a solid grammatical framework for analyzing new media forms and provides at least the beginnings of a language we can use to talk about it that doesn't currently exist within the broader field of study. It often feels like these forms are evolving so quickly that no sooner does one term become established than another comes to take its place (see 'viral', 'transmedia' and 'spreadable media'). Atkinson takes the time to outline 
recurring genres and themes, narrative devices and participation modalities which can help to better understand and discuss how emerging cinema is produced and consumed. As she notes, this is difficult because we currently lack the appropriate semiotics to discuss and analyse these complex, emerging and fluid forms, but Beyond the Screen marks a significant step towards developing a language that may yet have longevity. Moreover, it does so having taken into account textual, industrial and audience perspectives on these 'emerging cinemas' with dexterity, which very few other accounts can be said to have achieved.

Stephanie Janes

Royal Holloway, University of London

Lower Flat

3 Quentin Road

Lewisham

London

SE13 5DQ

Stephanie.Janes@rhul.ac.uk

07954577881 